\title{
The Nitrogen cycle during the Cryogenian interglacial period- Implications from the Datangpo Formation of a drillcore, South China
}

\author{
TING-TING LI ${ }^{1}$, GUANG-YOU ZHU ${ }^{1}$ \\ ${ }^{1}$ Research Institute of Petroleum Exploration and \\ Development, PetroChina, Beijing 100083, China \\ The Cryogenian interglacial Period was separated by \\ two global-scale glaciations, well-known as the Sturtian \\ glaciation ( $715 \mathrm{Ma}-660 \mathrm{Ma})$ and the Marinoan \\ glaciation ( $650 \mathrm{Ma}-635 \mathrm{Ma})$, which has documented \\ dramatic changes of climate, oceanic environment and \\ biological evolution. Previous studies have reported \\ extensive anoxia that prevailed during the interglacial \\ period, but reports about biological records were very \\ limited, thus causing a difficulty in evaluation of the \\ link between redox environment and oceanic life. As an \\ essential nutrient for primary productivity, nitrogen, \\ especially its cycling opens a window for understanding \\ the co-evolution of the Earth's environment and life. \\ Here we present nitrogen isotope and organic isotope, \\ iron-speciation data of the Cryogenian interglacial \\ Datangpo Formation from a drillcore in South China. \\ The result shows that the lower member (LM) with high \\ TOC contents (mean $=2.0 \%$ ) was deposited in euxinic \\ bottom waters. The upper member (UM) with low TOC \\ contents $(<0.6 \%)$, which is composed of gray shale and \\ siltstone, was mostly deposited under oxic conditions, \\ possibly with some anoxic episodes. Both of the two \\ members, are characterized by positive nitrogen isotope \\ values $(+2.9 \%$ o $+8.3 \%$ ) , indicating a nitrogen cycle \\ dominated by partial denitrification. A compilation of \\ nitrogen isotope data from modern and ancient \\ sediments show that both Cryogenian interglacial and \\ Post-Marinoan deposits have a similar mode with the \\ modern oxygenated ocean in $\delta 15 \mathrm{~N}$ distribution, which \\ at least implies appreciable NO3- availability for \\ animals in these post-glacial oceans.
}

